\title{
Competency-based medical education in two Sub-Saharan African medical schools
}

This article was published in the following Dove Press journal:

Advances in Medical Education and Practice

9 December 2014

Number of times this article has been viewed

\author{
Elsie Kiguli-Malwadde ${ }^{1,2}$ \\ E Oluwabunmi Olapade- \\ Olaopa ${ }^{1,3}$ \\ Sarah Kiguli \\ Candice $\mathrm{Chen}^{4}$ \\ Nelson K Sewankambo ${ }^{2}$ \\ Adesola O Ogunniyi ${ }^{3}$ \\ Solome Mukwaya' \\ Francis Omaswa' \\ 'African Centre for Global Health \\ and Social Transformation, Kampala, \\ Uganda; ${ }^{2}$ Makerere University, College \\ of Health Sciences, Kampala, Uganda; \\ ${ }^{3}$ College of Medicine, University of \\ Ibadan, Ibadan, Oyo State, Nigeria; \\ ${ }^{4} \mathrm{School}$ of Public Health and Health \\ Services, The George Washington \\ University, Washington, DC, USA
}

Correspondence: Elsie Kiguli-Malwadde PO Box 9519, Kampala, Uganda Email kigulimalwadde@gmail.com
Background: Relatively little has been written on Medical Education in Sub-Saharan Africa, although there are over 170 medical schools in the region. A number of initiatives have been started to support medical education in the region to improve quality and quantity of medical graduates. These initiatives have led to curricular changes in the region, one of which is the introduction of Competency-Based Medical Education (CBME).

Institutional reviews: This paper presents two medical schools, Makerere University College of Health Sciences and College of Medicine, University of Ibadan, which successfully implemented CBME. The processes of curriculum revision are described and common themes are highlighted. Both schools used similar processes in developing their CBME curricula, with early and significant stakeholder involvement. Competencies were determined taking into consideration each country's health and education systems. Final competency domains were similar between the two schools. Both schools established medical education departments to support their new curricula. New teaching methodologies and assessment methods were needed to support CBME, requiring investments in faculty training. Both schools received external funding to support CBME development and implementation.

Conclusion: CBME has emerged as an important change in medical education in Sub-Saharan Africa with schools adopting it as an approach to transformative medical education. Makerere University and the University of Ibadan have successfully adopted CBME and show that CBME can be implemented even for the low-resourced countries in Africa, supported by external investments to address the human resources gap.

Keywords: CBME, medical education, competency domains, competencies, curricular reforms

\section{Background}

The environment in Sub-Saharan Africa presents unique challenges to improving health, strengthening health systems, and educating future health care workers, including physicians. Sub-Saharan Africa suffers from disproportionate disease burden. Twelve percent of the world's population lives in Sub-Saharan Africa, yet the region suffers $27 \%$ of the world's total burden of disease, has only $3.5 \%$ of the world's health care workforce, and $1.7 \%$ of the world's physicians in an environment of limited resources. ${ }^{1}$ It is therefore apparent that health professions training in Africa must undergo changes to overcome these challenges.

Currently, there has been an increase in global interest in strengthening human resources for health in the region. Recent years have also seen increasing calls for transformation of health professionals' education to better meet the continued and 
evolving health needs of communities. ${ }^{2}$ The number one recommendation of the recent Commission on the Education of Health Professionals was the "adoption of competencybased curricula that are responsive to rapidly changing needs". ${ }^{2}$ Increasing adoption of competency-based medical education (CBME) by health systems, accrediting bodies, and medical schools represents an important response to the calls for educational reform. ${ }^{3}$ Governments must strengthen their health systems, and one of their strategies should be improving curricular and skills of their workers. Addressing the health systems challenges will require a combination of an increase in the number of health care professionals especially doctors, and the modification of the skill set possessed by these professionals to improve their ability to function in their communities. Medical schools are ultimately expected to drive the improvement of the health of the people in their communities. As such, these institutions play a significant role in the efforts to respond to the health-workforce challenges in the subcontinent and in so doing become more socially accountable. ${ }^{4}$ One major vehicle for effecting these changes is the modification of the methods of instruction of health professions training to make the graduates more socially responsive and therefore, better fit for practice.

CBME is an outcome-based education approach that focuses on the result of the educational process, not the process itself. This has been explained in different ways by different authors. ${ }^{3,5}$ A 2010 literature review suggests the following definition of Competency-Based Education:

Competency-Based Education (CBE) is an approach to preparing physicians for practice that is fundamentally oriented to graduate outcome abilities and organized around competencies derived from an analysis of societal and patient needs. It de-emphasizes time-based training and promises greater accountability, flexibility, and learner-centeredness. ${ }^{6}$

The authors of the above definition state that there is little agreement on many aspects of CBME and that is why they convened this partnership to examine conceptual issues and current debates on CBME. ${ }^{6}$

Curricular reform to achieve CBME requires matching the educational experience to clearly defined societal and patient needs. In addition, a competency should be measurable and use a standard for judging it that is not dependent on the performance of other learners. ${ }^{7}$ These kinds of changes can require significant changes in institutional culture and processes. CBME has been increasingly adopted by the international medical education community in the past two decades. $^{5}$

Sub-Saharan Africa is now known to have at least 170 medical schools ${ }^{8}$ and CBME has begun to take root in the region. However, contributions to the education literature from the subcontinent are relatively scanty, ${ }^{9}$ and little has been written on CBME initiatives and the unique circumstances and requirements of implementing CBME in a low-resource environment like Sub-Saharan Africa. A few examples include one from Muhimbili University of Health and Allied Sciences on developing eLearning technologies to implement CBME and the other on developing a competencybased curriculum for eye care managers in Sub-Saharan Africa. ${ }^{10,11}$ Gruppen et al also mention CBME in low-resource settings and recommend that it should be contextual and not just transferred from what is done in the developed countries. ${ }^{12}$ In this paper, we describe the process by which two public medical schools, the Makerere University College of Health Sciences and the College of Medicine at the University of Ibadan (CMUI), have successfully introduced CBME in their undergraduate curricula.

\section{Institutional reviews}

We present two reviews of the above-mentioned medical schools implementing CBME in Sub-Saharan Africa. The two schools were identified as two early implementers of CBME through the Medical Education Partnership Initiative (MEPI), a US government funded program to support medical school development in Sub-Saharan Africa. The principal investigator contacted the curriculum chair at each of the two schools and both agreed to participate as collaborators of this study. The principal investigator conducted structured interviews in person with each of the curriculum chairs. Interviews followed a guide and collected information on curriculum review process, implementation and evaluation. Case reports were reviewed for accuracy by curriculum chairs and additional documentation, such as competency domains and curriculum documents, were requested and provided when appropriate.

\section{Study sites \\ Makerere University}

Makerere University is one of the oldest universities in Africa, and for a long time, it was the only university in Uganda. It was established in 1922 as a technical school. Over the years, it transitioned into a college and later into an institution of higher education, offering various courses. The university transitioned from the faculty-based to the collegiate system 
in 2011 and has nine constituent colleges and one school. The College of Health Sciences is one of them.

Uganda has a rapidly growing population of 32 million people with a low national per capita income of US\$ 1,520 . Uganda's life expectancy is 50 years and the doctor to patient ratio is 1:24,000. In Uganda, the commonest causes of morbidity and mortality are HIV/AIDS, malaria, and lower respiratory diseases; however, noncommunicable diseases are on the increase. ${ }^{13}$

\section{University of Ibadan}

The University of Ibadan (UI) is the oldest Nigerian university. It was founded as a college in 1932 and became a university in 1948. The University of Ibadan became an independent university in 1962. Besides the College of Medicine, it has ten other faculties.

Nigeria has a large population of 169 million people with a national per capital income of US\$2,450 and a life expectancy of 54 years. The doctor to patient ratio is $1: 3,500$. The main causes of mortality and morbidity are malaria, lower respiratory infections followed by HIV, and other infectious diseases. ${ }^{14}$

\section{Makerere University, College of Health Sciences}

Founded as a Medical School in 1924, Makerere University College of Health Sciences (MakCHS) is one of the oldest medical education institutions in Sub-Saharan Africa. The curriculum was initially a traditional discipline-based model with didactic courses in the initial years focused on the basic sciences and clinical rotations in later years organized by specialties. Course objectives were focused on knowledge and skills acquisition based on the course topics. Student evaluations were mainly summative.

\section{Curriculum revision process}

In an effort to produce graduates who would better meet the health needs of the Ugandan society, Makerere University in collaboration with John Hopkins University convened stakeholder meetings from 2008 to 2010. Stakeholders included medical school leaders and faculty, students, alumni, health care providers, government representatives from the Ministry of Health, Ministry of Education, District Directors of Health, employers of graduates, community leaders, and international development partners. Medical school leaders included those from other Ugandan medical schools. The University conducted an extensive process of needs assessment, curriculum review, literature review and surveys, key informant interviews, and focus group discussions with key stakeholders. The needs assessment involved a number of methods, mainly qualitative, interviewing District Health officers, and other employees of the graduates, officials from Ministry of Health, development partners, and representatives of community, faculty, and graduates. The process specifically identified that there was need to revise curricula into competency-based curricula to address the gaps. ${ }^{15}$

The needs assessment identified a number of gaps in the skills of graduates particularly in professionalism, leadership and management, communication, and interpersonal skills. Several consensus meetings were conducted that finally led to the development and adoption of competencies to guide medical education efforts in Uganda (Table 1).

MakCHS then underwent a process of curriculum reform. Individual courses were designed to reflect as many competencies as possible. An interdisciplinary team of experts developed descriptions of the course objectives, expected outcomes, course content, mode of delivery, assessment methods, contact hours based on the health needs of the population, required level of competencies in the spiral of the curriculum, time available in the academic calendar. Approval by content experts was sought.

\section{Implementation}

New methods of teaching were needed to translate the desired learning objectives and competency domains into education. These methods include problem-based learning in the preclinical years and case-based learning in the clinical years; skills laboratory training; practical sessions; self-directed learning; use of information communication technology; clinical pathological conferences; clinical audits; community-based education, research, and service; early clinical exposure; and community projects. These methods were integrated with traditional methods, including ward teaching, lectures, journal clubs, and grand rounds.

These changes required significant faculty development. Faculty required training in what CBME is, how to teach especially small groups, and assessment training, including how to give feedback, use portfolios, and objective structured clinical/practical examinations. This has required MakCHS to rethink their faculty development strategy, and they are in the process of forming a Medical Education Department. The medical education unit is expected to take over faculty development activities, but in the meantime, many faculty members have had training in health professions education at masters and fellowship level. They are responsible for conducting faculty development in the area 
Table I Makerere University medical student competency domains

\begin{tabular}{|c|c|}
\hline Competency domain & Description \\
\hline Medical knowledge & $\begin{array}{l}\text { The ability to recall knowledge of human structure, function, development, and pathophysiology; } \\
\text { and of epidemiological and social-behavioral sciences and apply it in providing care to individuals, } \\
\text { families, and society. }\end{array}$ \\
\hline Population health & $\begin{array}{l}\text { Demonstrate the ability to work with the community to promote health, prevent disease, } \\
\text { and empower communities in order to produce a healthy population. }\end{array}$ \\
\hline Critical inquiry and scientific methods & $\begin{array}{l}\text { Demonstrate an understanding and use of scientific theory, methodology, and critical thinking skills } \\
\text { to conduct research, interpret findings, and apply these to improve individual, family, and community } \\
\text { health. }\end{array}$ \\
\hline Interpersonal and communication skills & $\begin{array}{l}\text { Demonstrate effective interpersonal and communication skills with a wide range of individuals and } \\
\text { groups in order to provide appropriate health care. }\end{array}$ \\
\hline Clinical skills and patient care & $\begin{array}{l}\text { Demonstrate effective use of motor and cognitive skills in diagnosis, management, } \\
\text { and prevention of common health problems encountered in patient care. }\end{array}$ \\
\hline Leadership and management skills & Demonstrate appropriate leadership and management skills for effective and efficient health systems. \\
\hline $\begin{array}{l}\text { Continuous improvement } \\
\text { of care through reflective practice }\end{array}$ & $\begin{array}{l}\text { Demonstrate the ability to investigate and evaluate their practice, appraise, and assimilate scientific } \\
\text { evidence, and to continuously improve health care based on constant self-evaluation and lifelong } \\
\text { learning. }\end{array}$ \\
\hline Professionalism and ethical practice & $\begin{array}{l}\text { Demonstrate through knowledge and behavior, a commitment to the highest standards of clinical } \\
\text { care, ethics, integrity, and accountability to the patient, society, and the profession. }\end{array}$ \\
\hline Health systems management & $\begin{array}{l}\text { Demonstrate an understanding of the composition, organization, economics and other interrelated } \\
\text { dynamics of health service provision and the ability to practice within the health system. }\end{array}$ \\
\hline
\end{tabular}

of health professions education. This has been done mainly through holding workshops.

There are 500 students on the new curricula at MakCHS, which include medical students and all other undergraduate health professional students at the college (Dentistry, Pharmacy, Radiography, Nursing, Biomedical Science, and Environmental Science) whose curricula were also revised to be competency based. The process has also spilled over to some postgraduate curricula that have been revised in the same way.

\section{Evaluation}

Methods of student assessment had to change with CBME. Some assessment of knowledge is still through multiple choice questions and extended matching questions. However, short essays (used both formatively and summatively), objective structured clinical examinations, portfolios, students' write ups, project write ups, peer assessments, and feedbacks are all being used as well.

Program evaluation is ongoing through evaluation of course units, and plans are already underway to have an evaluation at the end of the 5 years.

\section{College of Medicine, University of Ibadan}

The CMUI is Nigeria's oldest medical school. It was established at the inception of its parent public university in 1948 and since then its medical curriculum has been revised several times. However, the philosophy and methods of teaching and assessment were largely unchanged during these revisions. The curriculum was a traditional one, science based mainly didactic in the preclinical years and specialty based in the clinical years.

\section{Curriculum revision process}

Between 2000 and 2010, a major revision of the CMUI MBBS curriculum was undertaken with the aim of producing an instrument for medical instruction that would meet current and future national health needs and global standards. The revision of CMUI medicine curriculum was done in four phases.

Phase one focused on building up of human resource capacity in medical education and increasing awareness among the stakeholders on the need for a wholesome review of the medical curriculum. To this end, seven CMUI academic staff acquired medical education skills in the IFMER $^{\circledR}$, FAIMER $^{\circledR}$, and Open University programs starting in $2000 .{ }^{16}$ In 2004, the university was successfully awarded a MacArthur Foundation grant to revise the medical curriculum.

Phase two of the project was a review of the existing curriculum. After identification of current and future medical education and national health/medical practice needs, the philosophy of the new curriculum was determined, and the design of appropriate methods of instruction and assessment were agreed on. Questionnaires were administered to students, selection interviews for medical school admission were evaluated, and focus group discussions were conducted with stakeholders. The data obtained from these studies ${ }^{17,18}$ was used in the 
development of a draft template for an integrated, system-based, competency-based, community-oriented curriculum. This curriculum template was sent to all academic and administrative units of the college and the student bodies for their input.

In phase three, the revised curriculum template was developed into a full curriculum. During this process, the curricula of the component departments and disciplines of the MBBS were revised into an integrated, system-based, person-centered, community-oriented, and competencydriven instrument with problem-based learning components. The final document was approved by the CMUI Academic Board and ratified by the University Senate in $2010 .{ }^{19}$

\section{Implementation}

The fourth phase of the process has been implementation of the new curriculum, which commenced with the students who began preclinical instruction in the 2011/2012 academic year. There are 300 students in the preclinical years in the new MBBS curriculum. This process has been supported through external grant funding (MEPI).

To ensure effective implementation, CMUI set up the MBBS Curriculum Implementation Committee, which later metamorphosed into the Medical Education Unit. This unit has guided the departments and the college administration on the acquisition of infrastructure for the curriculum and organized faculty development workshops focused on the teaching and assessment methods of the new curriculum. One of the major functions of the unit is the monitoring and evaluation of the curriculum-implementation process.

Similar to MakCHS, has been the need for extensive retraining of the CMUI teaching and nonteaching staff in the new teaching and assessment methods. This has proved to be both time and resource (human and financial) intensive. A challenge has been the fact that the College is presently running two different curricula concurrently, placing additional pressure on the teachers, the students, and the CMUI executives. In addition, the students on both sides of the curriculum have required counseling and mentoring to reassure them that they are being well-trained regardless of their instrument of instruction.

\section{Evaluation}

The assessment goal at CMUI is to ensure that the students have achieved the competencies required by the program. It aims at assessing the students at the level of "show how/does" with both formative and summative methods of assessment. The revised CMUI Curriculum uses similar assessment tools to MaKCHS described earlier.
Evaluation of the new curriculum, though challenging, has been identified as a very important component of the change. It is an ongoing process that has started with evaluation of the perceptions of the students and teachers.

\section{Discussion}

The transformation of health professions education especially in low- and mid-income countries is attracting widespread interest among stakeholders including medical educators. ${ }^{2}$ Our two cases illustrate the processes needed and the areas of focus that can inform any institution contemplating introduction of CBME. These include defining the required competency domains and competencies, curriculum development process, curriculum implementation units and faculty training, evaluation and feedback, and mobilizing resources to support each of the above obligations.

Both CMUI and MakCHS used similar processes in developing their individual CBME curricula. The process involved identification of the skill sets required for graduates; explicit attention to the required competencies and their components; determination of the milestones along a development path for the competencies; selection of educational activities, experiences, and instructional methods; selection of assessment tools to measure progress towards the milestones; and the design an outcome-based evaluation of the program.

The processes of developing competency domains and the desired competencies at both schools were similar with extensive involvement of all stakeholders from the university, the affiliated teaching hospitals, government, and international partners. The developed competencies had to take into consideration each country's health needs and health and education systems. It was noted that the overarching competency domains identified by both schools were quite similar to those of the CanMeds suggesting some universality of CBME. However, it must be acknowledged that knowledge of the CanMeds by the stakeholders could have influenced their choices.

It is notable that both CMUI and MakCHS established medical education departments to oversee implementation of their new curricula. Both schools found curriculum reform, implementation, and maintenance required dedicated faculty trained and experienced in pedagogy, as well as ongoing faculty development for all teachers. Faculty needed to understand the relatively new paradigm of CBME and development of appropriate teaching methods and materials. The two schools have taken the issue of faculty development seriously and have invested heavily in training programs to 
empower them to lead the change process. This trained faculty has then gone on to train other teaching and nonteaching staff from the institutions. Interestingly, the fact that similar curriculum reforms are taking place concurrently in these two schools provides them with a unique opportunity to learn from each other's experiences. In this regard, interactions at student, faculty, and institutional levels may be facilitated by the fact that both schools are beneficiaries of the MEPI grant that promotes such south-south partnerships refers to exchange of resources, technology and knowledge between developing countries.

Program evaluation and feedback to guide curriculum implementation and further revision is an important and, in most cases, a challenging part of curriculum development. Both schools are using similar multiple assessment methods, contributing to formative and summative evaluation. However, evaluation has been recognized as a weakness at both institutions and needs additional planning and constant attention as an integral part of the implementation process.

All changes require resources and yet health systems worldwide are under resourced for their teaching role. ${ }^{20}$ The World Health Organization's report from 2006 states that in order to improve the production capacity of the country in the scaling up of health workforce, three things are important: developing infrastructure, ensuring that there is enough faculty to provide a range of teaching methodologies and appropriate educational content, and improving organization/ operational capacities. ${ }^{21}$ The major challenge of severely constrained resources in the teaching facilities in Sub-Saharan Africa was re-emphasized recently in the SAMSS study. ${ }^{8}$ Both MakCHS and CMUI received external funding to support their curriculum reforms. Without external funding, it may have been challenging for both institutions to introduce the changes needed to support these transformative curricula reforms. Both institutions are already planning for sustainability of CBME beyond the project funding, for example, by engaging their governments, non-Govermental organisations (NGOs), the alumni and private sector, as highly valued stakeholders who should contribute more funding to higher educational institutions. However, one cannot exclude the fact that because the processes were largely funded externally, external forces may have influenced the changes.

\section{Conclusion}

CBME has emerged as an important change in medical education in Sub-Saharan Africa in the past few years with some schools adopting it as an approach to transformative medical education. The two African schools described above have successfully adopted CBME and show that CBME can be implemented even for the low-resourced countries in Africa. This is also an illustration of what external investments are beginning to achieve as a contribution to addressing the human resources gap. The schools are still in the early stages of implementation and need to strengthen evaluation of the programs.

\section{Acknowledgments}

The authors acknowledge the US Government, President's Emergency Plan for AIDS Relief, National Institutes of Health, Health Resources and Services Administration, John T and Catherine D MacArthur Foundations, George Washington University, African Center for Global Health and Social Transformation (ACHEST), Makerere University, Medical Education for Equitable Services to all Ugandans Consortium, University of Ibadan, and the whole MEPI community for making this work possible.

\section{Author contributions}

EKM, EOOO, and SK have made substantial contributions to conception and design of the article, acquisition of data for case reports and critically revised the manuscript. $\mathrm{CC}$, NKS, AOO, MS, and FO have been involved in drafting the manuscript or revising it critically for important intellectual content; and all authors have given final approval of the version to be published.

\section{Disclosure}

The authors declare that they have no competing interests.

\section{References}

1. Chen C, Buch E, Wassermann T, et al. A survey of Sub-Saharan African medical schools. Hum Resour Health. 2012;10:4.

2. Frenk J, Chen L, Bhutta ZA, et al. Health professionals for a new century: transforming education to strengthen health systems in an interdependent world. Lancet. 2010;376(9756):1923-1958.

3. Swing SR. The ACGME outcome project: retrospective and prospective. Med Teach. 2007;29(7):648-654.

4. Boelen C. Adapting health care institutions and medical schools to societies' needs. Acad Med. 1999;74(8):S11-S20.

5. Frank JR, Danoff D. The CanMEDS initiative: implementing an outcomes-based framework of physician competencies. Med Teach. 2007;29(7):642-647.

6. Frank JR, Snell LS, Cate OT, et al. Competency-based medical education: theory to practice. Med Teach. 2010;32(8):638-645.

7. Albanese MA, Mejicano G, Mullan P, Kokotailo P, Gruppen L. Defining characteristics of educational competencies. Med Educ. 2008;42(3):248-255.

8. Mullan F, Frehywot S, Omaswa F, et al. The medical education partnership initiative: PEPFAR's effort to boost health worker education to strengthen health systems. Health Aff (Millwood). 2012;31(7):1561-1572.

9. Greysen SR, Dovlo D, Olapade-Olaopa EO, Jacobs M, Sewankambo N, Mullan F. Medical education in sub-Saharan Africa: a literature review. Med Educ. 2011;45(10):973-986. 
10. Nagunwa T, Lwoga E. Developing an eLearning strategy to implement medical competency based curricula: experiences from Muhimbili University of Health and Allied Sciences. International Journal of Education and Development Using Information and Communication Technology (IJEDICT). 2012;8(3):7-21.

11. Du Toit R, Cook C, Minnies D, Brian G. Developing a competency based curriculum for eye care managers in Sub Saharan Africa. Rural Remote Health. 2010;10(2):1278.

12. Gruppen LD, Mangrulkar RS, Kolars JC. The promise of competencybased education in the health professions for improving global health Hum Resour Health. 2012;10:43.

13. Uganda Bureau of Statistics. Statistical Abstract; 2012. Available from http://www.ubos.org/onlinefiles/uploads/ubos/pdf\%20documents/ abstracts $/ 2012 \% 20$ Statistical\%20Abstract.pdf.

14. WHO African Region Nigeria. 2014. Available from: http://www.who. int/countries/nga/en/.

15. Kiguli S, Baingana R, Paina L, et al. Situational analysis of teaching and learning of medicine and nursing students at Makerere University College of Health Sciences. BMC Int Health Hum Rights. 2011;11(Suppl 1):S3.
16. Afolabi B, Olapade-Olaopa EO. International training in medical education - the FAIMER institute 2002 fellowship experience. Afr $J$ Med Med Sci. 2006;35(1):59-67.

17. Olapade-Olaopa OJ, Dania S, Soyannwo OA, Adeniyi FAA. Study processes of first year clinical students of the College of Medicine, University of Ibadan, Ibadan Nigeria. Afr J Med Med Sci. 2004;35(4):431-435.

18. Olapade-Olaopa E. Curriculum change and the College of Medicine, University of Ibadan, Ibadan Nigeria. Afr J Med Med Sci. 2006;35(3): 395-405.

19. The 2010 MBBS Curriculum of the College of Medicine UoI. In: Olapade-Olaopa E, editor. Ibadan: Office of the Provost, CMUI; 2010.

20. Harris P, Snell L, Talbot M, Harden RM. Competency-based medical education: implications for undergraduate programs. Med Teach. 2010;32(8):646-650.

21. World Health Organisation. Working Together for Health: the World Health Report 2006. Geneva: World Health Organization; 2006:3-15.
Advances in Medical Education and Practice

\section{Publish your work in this journal}

Advances in Medical Education and Practice is an international, peerreviewed, open access journal that aims to present and publish research on Medical Education covering medical, dental, nursing and allied health care professional education. The journal covers undergraduate education, postgraduate training and continuing medical education

\section{Dovepress}

including emerging trends and innovative models linking education, research, and health care services. The manuscript management system is completely online and includes a very quick and fair peer-review system. Visit http://www.dovepress.com/testimonials.php to read real quotes from published authors.

Submit your manuscript here: http://www.dovepress.com/advances-in-medical-education-and-practice-journal 